Braz J Med Biol Res, September 2011, Volume 44(9) 947-957

doi: 10.1590/S0100-879X2011007500084

Nitric oxide synthesis and biological functions of nitric oxide released from ruthenium compounds

A.C. Pereira, M. Paulo, A.V. Araújo, G.J. Rodrigues and L.M. Bendhack

The Brazilian Journal of Medical and Biological Research is partially financed by

\section{足CNPq}

da Ciência e Tecnologio

Institutional Sponsors

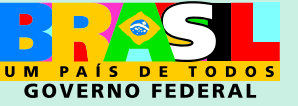

DFAPESP
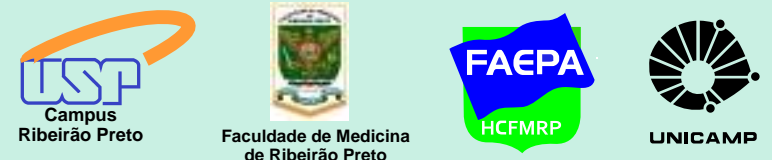

ФSHIMADZU

Explore High - Performance MS

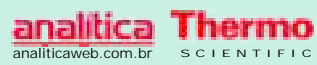




\title{
Nitric oxide synthesis and biological functions of nitric oxide released from ruthenium compounds
}

\author{
A.C. Pereira ${ }^{1}$, M. Paulo ${ }^{1}$, A.V. Araújo ${ }^{2}$, G.J. Rodrigues ${ }^{2}$ \\ and L.M. Bendhack ${ }^{1}$ \\ ${ }^{1}$ Departamento de Física e Química, Faculdade de Ciências Farmacêuticas de Ribeirão Preto, \\ Universidade de São Paulo, Ribeirão Preto, SP, Brasil \\ ${ }^{2}$ Departamento de Farmacologia, Faculdade de Medicina de Ribeirão Preto, \\ Universidade de São Paulo, Ribeirão Preto, SP, Brasil
}

\begin{abstract}
During three decades, an enormous number of studies have demonstrated the critical role of nitric oxide (NO) as a second messenger engaged in the activation of many systems including vascular smooth muscle relaxation. The underlying cellular mechanisms involved in vasodilatation are essentially due to soluble guanylyl-cyclase (sGC) modulation in the cytoplasm of vascular smooth cells. sGC activation culminates in cyclic GMP (cGMP) production, which in turn leads to protein kinase $\mathrm{G}$ (PKG) activation. NO binds to the sGC heme moiety, thereby activating this enzyme. Activation of the NO-sGC-cGMP-PKG pathway entails $\mathrm{Ca}^{2+}$ signaling reduction and vasodilatation. Endothelium dysfunction leads to decreased production or bioavailability of endogenous NO that could contribute to vascular diseases. Nitrosyl ruthenium complexes have been studied as a new class of NO donors with potential therapeutic use in order to supply the NO deficiency. In this context, this article shall provide a brief review of the effects exerted by the NO that is enzymatically produced via endothelial NO-synthase (eNOS) activation and by the NO released from NO donor compounds in the vascular smooth muscle cells on both conduit and resistance arteries, as well as veins. In addition, the involvement of the nitrite molecule as an endogenous NO reservoir engaged in vasodilatation will be described.
\end{abstract}

Key words: Nitric oxide; Vasodilatation; Ruthenium complex; NO-synthase; Resistance artery; Conduit vessel

\section{Introduction}

This review will highlight the role played by endogenous nitric oxide (NO) generated in the vascular endothelial cells via endothelial NO-synthase (eNOS) activation and by NO released from $\mathrm{NO}$ donor compounds in the modulation of the sGC-cGMP-PKG pathway (soluble guanylyl-cyclase, cyclic GMP, protein kinase $\mathrm{G}$ ) and consequent induction of vasodilatation. NO production is regulated by eNOS activation in response to increased cytosolic $\mathrm{Ca}^{2+}$ concentration $\left(\left[\mathrm{Ca}^{2+}\right] \mathrm{c}\right)$ in the endothelial cells that binds to calmodulin in order to activate eNOS. It has been shown that calcium ionophore $\mathrm{A} 23187$ has the ability to induce $\left[\mathrm{Ca}^{2+}\right] \mathrm{c} \mathrm{increase}$ in endothelial cells, with consequent $\left[\mathrm{Ca}^{2+}\right] \mathrm{c}$ decrease in the vascular smooth muscle cells (1). Interestingly, these effects are lower in the aorta of renal hypertensive rats than in the aorta of normotensive rats. Endothelial dysfunction can lead to NO deficiency, which is found in several cardiovascular diseases, such as hypertension. NO donors deliver NO, which acts as endogenous $\mathrm{NO}$ in vascular smooth muscle cells. Therefore, these compounds are suitable for either mimicking the endogenously produced $\mathrm{NO}$ or compensating for an endogenous NO deficiency. NO has been used as the pharmacological principle of nitrovasodilators that are therapeutically employed to promote vasodilatation. This is because, by activating sGC, NO maintains the vascular tone that is crucial for blood flow and arterial pressure regulation (2). A new ruthenium-derived NO donor has been reported to reduce mean arterial pressure in renal hypertensive rats, but not in normotensive rats (3). In addition, this hypotensive

Correspondence: L.M. Bendhack, Laboratório de Farmacologia, Faculdade de Ciências Farmacêuticas de Ribeirão Preto, USP, Av. do Café, s/n, 14040-903 Ribeirão Preto, SP, Brasil. Fax: +55-16-3602-4880. E-mail: bendhack@usp.br

Presented at the XV Simpósio Brasileiro de Fisiologia Cardiovascular, São Paulo, SP, Brazil, February 2-5, 2011.

Received February 14, 2011. Accepted June 1, 2011. Available online July 8, 2011. Published September 16, 2011. 
effect was obtained at a lower dose in severely hypertensive rats compared to moderately hypertensive rats. On the other hand, the vasorelaxation elicited by ruthenium-derived NO donor compounds was impaired in aortic rings isolated from renal hypertensive rats compared to normotensive rats. It has been demonstrated that impaired functional $\mathrm{K}^{+}$channel activity contributes to the deficient relaxation induced by the $\mathrm{NO}$ donor trans-[RuCl$\left([15] \mathrm{aneN}_{4}\right) \mathrm{NO}^{2+}(15$-ane $)$ in the aorta of renal hypertensive rats (4).

Continuous NO production and release play an important role in vascular homeostasis. For decades it has been thought that NO signaling is short-lived as a result of its rapid reaction with hemoglobin, which makes it difficult to understand how the effects of $\mathrm{NO}$ are conserved in the circulation. However, a series of studies have shown that $\mathrm{NO}$ bioactivity is maintained in blood. More recently, it has been suggested that $\mathrm{NO}$ can combine with other compounds that can function as stable NO carriers, thereby preserving its bioactivity. This could help explain how systemic events can occur far from the NO delivery site.

This review will summarize data available on the role played by the NO released from endothelial cells and the $\mathrm{NO}$ delivered by NO donors in inducing vascular relaxation in conduit and resistance arteries as well as veins.

\section{Nitric oxide synthesis}

$\mathrm{NO}$ is enzymatically generated via the action of NOsynthase isoforms (NOS). The first isoform discovered in the vascular endothelium (eNOS or NOS1) is present in a large number of cells other than endothelial cells and is the most important isoform participating in vascular relaxation. Endothelial cells play a pivotal role in vascular tone regulation through the synthesis and release of contractile and relaxing factors. The most important vasodilating factors are $\mathrm{NO}$, prostacyclin $\left(\mathrm{PGI}_{2}\right)$, and the endothelium-derived hyperpolarizing factor (EDHF). Among the mediators produced by endothelial cells, NO is considered to be the key physiological molecule involved in cardiovascular homeostasis. Both eNOS and neuronal NOS (nNOS or NOS2) are constitutive under physiological conditions. On the other hand, inducible NOS (iNOS or NOS3) is elicited by cytokines in pathophysiological conditions.

In 1980, Furchgott and Zawadzki (5) reported that rabbit aorta stimulated with acetylcholine was relaxed only in preparations with intact endothelium. In contrast, denuded rabbit aorta failed to relax in response to acetylcholine. The authors attributed relaxation to the endothelium-derived relaxing factor (EDRF). This was the first demonstration that the relaxation of isolated rabbit aorta and other blood vessels by acetylcholine requires the presence of endothelial cells (5). The authors determined that acetylcholine activates muscarinic $\mathrm{M}_{3}$ receptors in the endothelial cells with consequent EDRF release, which causes vascular smooth muscle cell relaxation. In fact, these findings represented a new era in vascular biology and in the vasodilatation process. Robert Furchgott, Louis Ignarro, and Ferid Murad were awarded the Nobel Prize for their discovery of the signaling properties of NO in 1998. Thus, over the last 20 years NO has become one of the most investigated molecules in the field of vascular biology.

Some years later, it was demonstrated that NO can be synthesized from L-arginine by cultured porcine aortic endothelial cells. It was proven that NO was released from endothelial cells stimulated with acetylcholine, bradykinin, and the calcium ionophore $\mathrm{A} 23187$ by infusion of L-arginine but not by $D$-arginine or any other closely related structural analogs.

NOS oxidizes the guanidine group of the enzyme substrate L-arginine, which results in NO production. NOS is inhibited by L-arginine analogs, and the NOS isoforms differ in terms of their sensitivity to these analogs. The enzymatic activity of NOS depends on a number of cofactors. This enzyme is regulated by tetrahydrobiopterin $\left(\mathrm{H}_{4} \mathrm{~B}\right), \mathrm{FAD}, \mathrm{FMN}$, and NADPH. NOS shares close homology with cytochrome $\mathrm{P}_{450}$ reductase including FAD, FMN, and NADPH binding. Arginine conversion to NO is catalyzed in two steps. In the first step, two-electron arginine oxidation occurs, forming $\mathrm{N}^{\omega}$-hydroxyarginine in a hydroxylation reaction that is accelerated by $\mathrm{H}_{4} \mathrm{~B}$ and requires calcium and calmodulin as activators. In the second step hydroxyarginine conversion to citrulline and NO takes place. In blood vessels, acetylcholine and other agonists activate receptors present on the membrane of endothelial cells. These receptors, in turn, activate the phosphoinositide cycle, which raises cytosolic calcium concentration and consequently stimulates NOS. Together, all of these events account for the NO-induced blood vessel dilatation. However, the cytosolic eNOS is catalytically inactive. The active non-phosphorylated enzyme is localized in the plasma membrane, where it generates the NO that is released into the extracellular environment. eNOS phosphorylation regulates its activity and subcellular distribution.

Recently, it has been reported that in both endothelial (6) and vascular smooth muscle cells (7) caveolae contribute to the vascular relaxation prompted by acetylcholine and NO donors, respectively. Caveolae are abundant in endothelial cells, where they regulate eNOS and NO production by interaction with caveolin-1, the structural caveolae protein (8). Caveolae disruption mimics endothelial dysfunction since the endothelium-induced vasodilatation mediated by NO becomes impaired.

Many studies have demonstrated that acute NOS inhibition in rats promotes hypertension, which is partially reversed by acute administration of L-arginine, the NOS substrate, but not by D-arginine. Therefore, a new model of persistent arterial hypertension induced by chronic NOS blockade with the NOS substrate analog L-NAME has been proposed, which functions as a non-selective eNOS inhibitor (9). Administration of L-NAME for 4 weeks 
in vivo increases arterial pressure and peripheral vascular resistance. Chronic eNOS inhibition causes endothelial dysfunction. This model clearly demonstrates that deficient $\mathrm{NO}$ generation can culminate in hypertension. To some extent, reduced NO bioavailability is a therapeutic goal in the treatment of cardiovascular disorders. Bernátová et al. (10) have reported that NO deficiency may be reversed either by interrupting L-NAME administration or by administering various antihypertensive drugs.

\section{Vascular effects of NO}

The multiple actions of $\mathrm{NO}$ rely on the interactions between NO and NO derivatives. The best understood interaction model is NO binding to the SGC metal heme center, which elicits sGC activation. In this case, NO binds to the ferrous state of the $\mathrm{SGC} \beta_{1}$ subunit prosthetic group, thereby inducing a conformational change that leads to sGC activation and consequent enhancement in cGMP production and cGMP-dependent vascular actions. The NO-sGC-cGMP signaling pathway regulates vasodilatation among other vascular functions.

In 1977, Mittal and Murad (11) published a study on sGC activation in numerous tissues by nitrite ion, nitroglycerin, nitroprusside, or NO. Guanylyl-cyclase catalyzes cGMP production from GTP. These authors also showed that partially purified rat liver sGC accounted for superoxide ion formation, and they proposed that the resulting superoxide ion and $\mathrm{H}_{2} \mathrm{O}_{2}$ furnished hydroxyl radicals, which can activate guanylyl-cyclase. This activation mechanism could explain the altered guanylyl-cyclase activity and cGMP production in tissues with oxidizing and reducing agents. This mechanism also permits physiological regulation of cGMP production when there is altered redox or free radical formation in tissues in response to hormones or other physiological substances.

Endothelial NO generation results in local formation of storage $\mathrm{NO}$ forms. The existence of stored NO forms was first examined by light-induced vasorelaxation. In our laboratory, it has been shown that photo induction of the complex 15-ane elicits complete aorta relaxation, which is due to NO delivery to the extracellular medium (12).

\section{Ruthenium compounds as vasodilating drugs}

$\mathrm{NO}$ is a stable free molecule that has been recognized as an effective compound in diverse physiological and pathological processes. Because some diseases have been associated with $\mathrm{NO}$ deficiency, great interest in exogenous $\mathrm{NO}$ donors that can deliver NO to specific targets under stimulation has arisen. The majority of NO donors synthesized to date bear a nitroso functional group within the molecule. In this context, ruthenium-based metal nitrosyls are perhaps among the most frequently studied complexes for NO delivery.

Nitrovasodilators induce vascular relaxation by NO generation. Some nitrovasodilators have been employed in the clinical setting, including organic nitrites or nitrates (e.g., amyl nitrite and nitroglycerin, respectively) and inorganic sodium nitroprusside (SNP). The organic nitrovasodilators are primarily used for the management of angina pectoris, whereas SNP is used for the immediate management of hypertensive emergencies. However, both classes of compounds exhibit undesirable side effects. Continuous exposure to nitroglycerin leads to the development of nitrate tolerance. High doses, prolonged use, or simply the use of SNP in patients with compromised hepatic function is associated with accumulation of cyanide and its metabolite thiocyanide. In this respect, new nitrosyl ruthenium compounds with improved pharmacological properties and that can act as NO donors have been developed as alternative vasodilators. Figure 1 shows the structure of the organic nitrates (nitroglycerin), inorganic nitrates (sodium nitroprusside) and ruthenium compounds as NO donors.

The ability of ruthenium to mimic the iron binding mode to many biological molecules, like serum transferrin and albumin, is believed to contribute to its generally low toxicity (13).

Countless nitrosyl ruthenium compounds have been investigated as NO donors, and it has been demonstrated that they can release NO under reduction by biological reducing agents or light (12-17). These ruthenium complexes were able to elicit aortic vasodilatation in physiological conditions $(4,15,16)$. The mechanism of vasodilatation promoted by ruthenium compounds has been attributed to NO release (18) and its action on smooth muscle cells, including sGC $(16,19)$ and $\mathrm{K}^{+}$channel $(4,16,19)$ activation, which in turn prompt decreased cytosolic calcium concentration $(7,18,20,21)$ and finally aorta relaxation.

The potency of some ruthenium compounds with regard to vascular relaxation induction is lower than that of SNP $(14,21)$. The time elapsed until some ruthenium complexes induce maximum relaxation is longer compared to SNP, which indicates that ruthenium compounds provide slow NO release (14). Figure 2 demonstrates how the compounds nitroglycerin, SNP and a ruthenium complex release NO. In vivo studies have demonstrated a hypotensive effect for some ruthenium complexes in different hypertensive animal models $(3,22)$, and a long-lasting hypotensive event was observed (3). This characteristic allows maintenance of low arterial pressure levels for long periods of time when ruthenium complexes are used, which is not possible in the case of SNP.

Acouple of ruthenium compounds have been developed as NO scavengers (23). For example, [Ru(Hedta) $\left(\mathrm{H}_{2} \mathrm{O}\right)$ ] (23) and trans-[Ru- $(\mathrm{Cl})\left(\mathrm{H}_{2} \mathrm{O}\right)($ cyclam $\left.)\right]$, in which $\mathrm{NO}$ can coordinate with ruthenium and replace the $\mathrm{H}_{2} \mathrm{O}$ molecule, have the ability to scavenge NO. The hypotensive effect induced by trans-[Ru- $(\mathrm{Cl})(\mathrm{NO})(\mathrm{cyclam})]\left(\mathrm{PF}_{6}\right)_{3}$ was abol- 


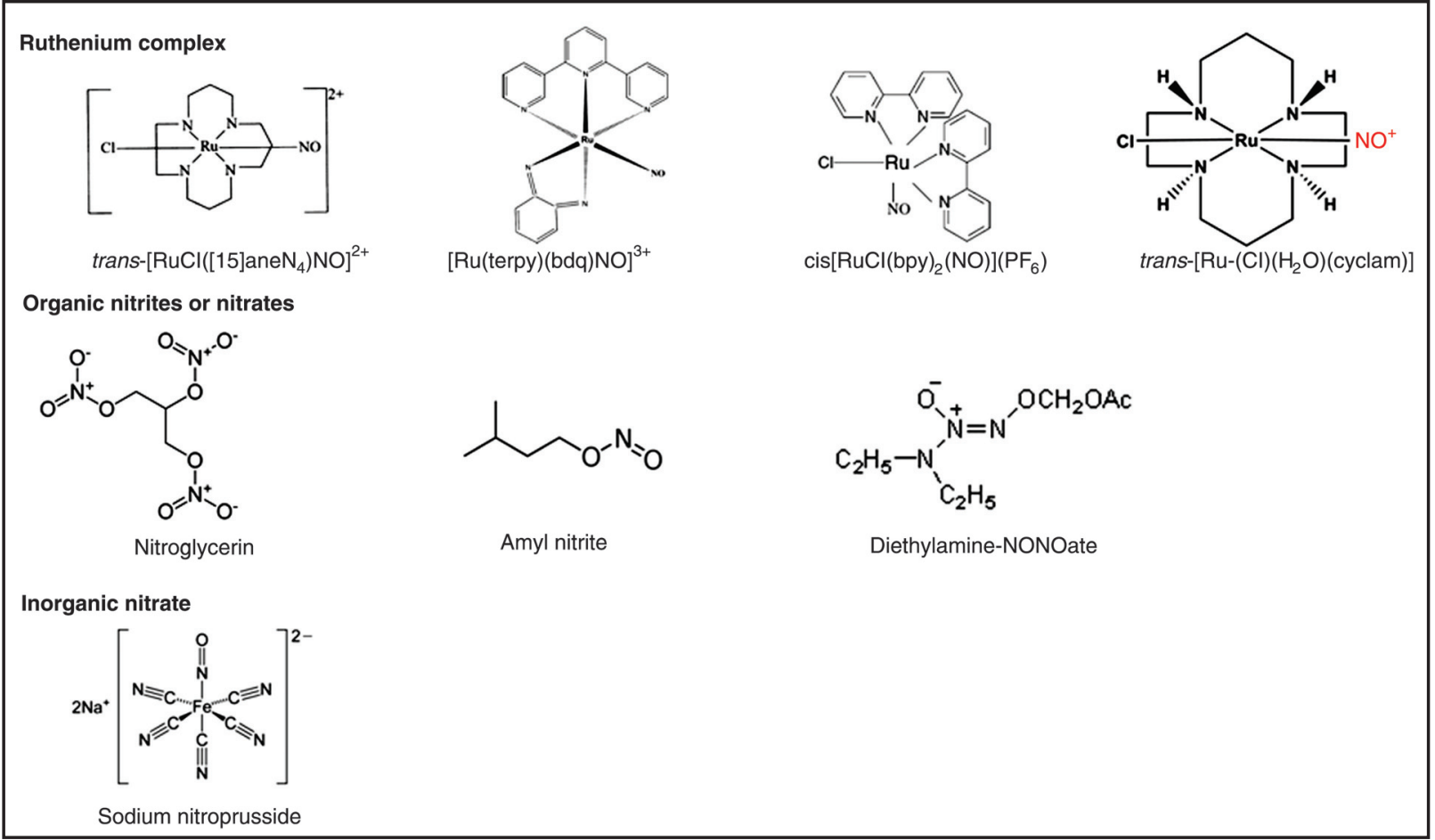

Figure 1. Structures of ruthenium complexes, organic nitrates and inorganic nitrates.

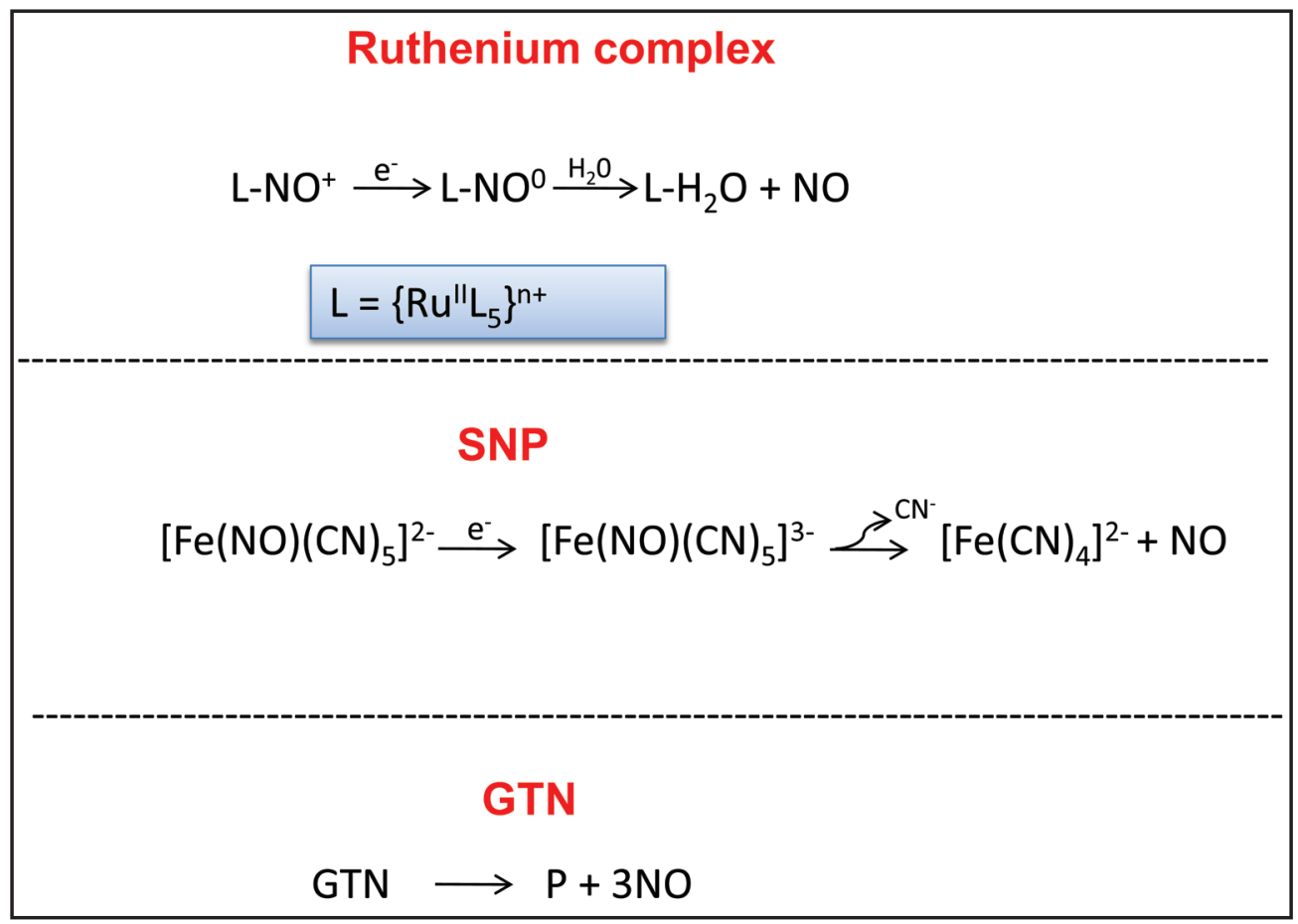

Figure 2. Nitric oxide (NO) release from ruthenium complexes, inorganic nitrate (sodium nitroprusside, SNP), and organic nitrate glyceryl trinitrate, GTN). L = ligand; $P$ = product. 
ished in the presence of the NO scavenger trans-[Ru- $(\mathrm{Cl})$ $\left(\mathrm{H}_{2} \mathrm{O}\right)$ (cyclam)]. The $\mathrm{NO}$ scavenging action displayed by the ruthenium complex could be explored in some pathological conditions, including septic shock, when there is high NO production by iNOS (24). Septic shock reflects the end of a continuous progressive pathophysiological deterioration culminating in hypotension and hypoperfusion. Hypoperfusion causes organ dysfunction, which leads to death. This pathological condition could be reversed by a ruthenium compound with NO scavenging action.

\section{Hypertension and endothelial dysfunction}

Resistance vessels are those that concentrate most of the pressure drop that must occur between large conduit arteries and capillaries. It has been underscored that their exact anatomical location is hard to define precisely (25), but they are commonly believed to encompass small arteries and arterioles, with diameters ranging from 15 to $300 \mu \mathrm{m}$.

Although all blood vessels must contribute to vascular bed resistance to some extent, in general it is the smaller arterial resistance vessels that present the greatest resistance and that are involved the most in regulating blood flow and capillary pressure.

In many pathological situations, in particular hypertension, resistance arteries are considered to play an important role in the etiology of the disease, and some authors have even suggested that development of resistance artery abnormalities could be the primary event in such processes.

Hypertension is usually associated with impaired endothelium-dependent vasorelaxation in response to several stimuli. Acetylcholine-induced vasorelaxation is blunted in conduit vessels from genetic and experimental hypertensive rodent models such as spontaneously hypertensive (SHR), deoxycorticosterone acetate (DOCA) salt-induced hypertensive, renovascular hypertensive, and angiotensin II-infused (ANG) hypertensive rats. However, both unchanged and impaired acetylcholine-induced vasorelaxation have been observed to occur in small mesenteric arteries from hypertensive rats in various experimental hypertension models such as DOCA salt, SHR, and ANG rats. Therefore, NO bioavailability in resistance arteries may be different from that observed in conduit vessels (26).

Many studies have reported on the similar acetylcholine-induced relaxation taking place in normotensive and hypertensive animals (27). The relaxation induced by acetylcholine was shown to be unchanged in small mesenteric arteries from renovascular (28) and DOCA-salt hypertensive rats (29).

In contrast, Liu et al. (27) have observed that acetylcholine-induced relaxation was diminished in small mesenteric arteries from SHR compared to normotensive rats. Kang et al. (26) observed that the acetylcholine-induced relaxation is less potent in small mesenteric arteries from rats made hypertensive by angiotensin II infusion.

Acetylcholine-induced relaxation is lower in basilar arteries, which are also resistance vessels, from SHR when compared to WKY (30).

As in the case of acetylcholine, there are some investigations showing that the NO donor-induced relaxation may remain unchanged or become impaired during hypertension. The relaxation prompted by the NO donor SNP has been demonstrated to continue unchanged in small mesenteric arteries from genetically hypertensive, SHR, and ANG rats $(26,27)$. Briones et al. (31) have reported that endotheliumdependent relaxations in response to bradykinin or sodium nitroprusside were similar in middle cerebral arteries from normotensive rats and SHR, while the endothelium-independent response to SNP was smaller in SHR middle cerebral arteries. Nevertheless, the relaxation induced by another $\mathrm{NO}$ donor, namely S-nitroso-N-acetylpenicillamine (SNAP), is less pronounced in coronary arteries from renovascular hypertensive rats compared to normotensive rats, although the measured NO was similar.

Concerning sGC activation, the relaxation promoted by the NO donor diethylamine-NONOate (DEA-NONOate) in mesenteric resistance arteries is less potent in the presence of ODQ, a selective inhibitor of the SGC isoform. ODQ also induced marked inhibition of relaxation responses to SNP in rat basilar artery.

The mechanisms involved in the NO-induced relaxation by resistance vessels are similar to the ones implicated in conduit vessels and seem to entail mainly the sGC/cGMP/ PKG pathway and $\mathrm{K}^{+}$channel activation. The latter may also be implied in NO-induced relaxation in resistance arteries. The relaxation elicited by DEA-NONOate was inhibited by the $\mathrm{K}^{+}$channel blocker 4-aminopyridine (4-AP) in rat basilar arteries. Moreover, a relatively low concentration of 4-AP, which is thought to be selective for inhibition of voltage-dependent $\mathrm{K}^{+}$channels (32) prompted basilar artery constriction, suggesting that under normal conditions activity of voltage-dependent $\mathrm{K}^{+}$channels may influence the basal tone of cerebral arteries in vivo. However, a role for ATP-sensitive $\left(\mathrm{K}_{\mathrm{ATP}}\right)$ or calcium-sensitive $\left(\mathrm{K}_{\mathrm{Ca}}\right) \mathrm{K}^{+}$ channels could not be observed.

The participation of $\mathrm{K}^{+}$channels (KIR) has also been evaluated. Schubert et al. (33) observed that the relaxation induced by SNP in rat tail small arteries was less potent in the presence of barium, a selective KIR blocker. In addition, SNP increased the amplitude of the KIR current, and this effect was almost abolished in the presence of barium, indicating that KIR participates in the SNP-induced relaxation.

The relaxation elicited by DEA-NONOate in mesenteric resistance arteries was less potent in the presence of charybdotoxin, suggesting involvement of calcium-activated $\mathrm{K}^{+}$ channels in this response (33).

Moreover, it has been observed that high extracellular $\mathrm{K}^{+}$concentration partly inhibited the relaxant effects of the 
NO donors DEA-NONOate and 3-morpholino-sydnonimine in rat basilar artery. While single applications of the $\mathrm{K}^{+}$ channel inhibitors tetraethyl-ammonium, glibenclamide, 4-AP, or $\mathrm{BaCl}_{2}$ did not affect the responses to DEA/NO, a combination of these inhibitors reduced the effects of DEANONOate. These data indicate that the relaxant effects of $\mathrm{NO}$ donors are partly mediated via $\mathrm{K}^{+}$channel activation, and that different $\mathrm{K}^{+}$channel types seem to be involved that function in a redundant manner and compensate for each other.

Some studies have reported alterations in the cellular mechanisms implicated in the relaxation taking place during hypertension. According to Kang et al. (26), $\mathrm{K}^{+}$ channel activation is impaired in small mesenteric arteries from ANG hypertensive rats, which is consistent with previous reports on SHR small mesenteric arteries. Moreover, Kang et al. (26) have shown that basal as well as acetylcholine-stimulated cGMP production is diminished in small mesenteric arteries from ANG hypertensive rats compared to normotensive rats. As demonstrated by Liu et al. (27), acetylcholine induced a significant increase in intracellular cGMP content from baseline in preparations from both genetically hypertensive New Zealand rats and normotensive rats. The extent of this increase was similar in these two rat strains. However, acetylcholine failed to increase the cGMP content in SHR arteries.

\section{Veins and vascular tone control: role of NO}

Compared to arteries, less attention has been given to the role of veins in vascular tone regulation. Nevertheless, two thirds of the circulating blood volume is in the veins at any given time. Veins and venules serve as a readily adjustable volume reservoir that can shift blood to or from the heart by both passive and active processes. The venous system contains about $70 \%$ of the blood volume, with approximately three-quarters of this volume being found within small veins and venules. The venous section of the cardiovascular system can be looked upon as a voluminous blood reservoir designed to preserve a proper inflow of blood into the heart during various cardiovascular adjustments. Venules and small veins are undoubtedly the most important blood reservoir within the circulatory system (34).

In contrast to arteries, veins have thinner walls, greater compliance, and valves to prevent retrograde flow. The major vein components are smooth muscle and the fibrous proteins collagen and elastin. The muscle fibers are responsible for contraction, while the collagen and elastin fibers account for the vessel's passive or viscoelastic properties. Veins have more collagen, but less elastin and smooth muscle compared to arteries. The venous system is the primary capacitance region in the body, and therefore alteration of its capacity greatly affects venous return and cardiac output. The venous tone or venomotor tone should not be confused with venous return. The body's venomotor tone is determined by venous compliance, venous resistance, and blood volume (35). Venous return, on the other hand, is controlled by cardiac as well as vascular factors, which include arterial and venous resistance, arterial and venous compliance, cardiac contractility, heart rate, and blood volume (35). Hence, the body venous tone is an important determinant of cardiac output. There are few studies on the venous system despite its importance in carbon monoxide and mean arterial pressure control. Increased venomotor tone and reduced compliance in peripheral veins shift blood to the small arteries, thereby elevating arterial blood pressure. Hypertensive humans and experimental animals have decreased venous capacitance because of reduced compliance (36).

The importance of the endothelium and of $\mathrm{NO}$ for the arterial circulation is well recognized. In the arterial circulation, endothelium-derived NO release is stimulated by shear stress and agonists such as acetylcholine, carbachol, and bradykinin (37). The role played by NO in venous tone regulation is less clear. Several studies have suggested that $\mathrm{NO}$ activity varies between different venous preparations. Vedernikov et al. (38) demonstrated marked endothelium-dependent relaxation in jugular, femoral, and mesenteric veins. However, such activity was not observed in the saphenous, portal, or inferior cava veins, despite preservation of endothelium-independent relaxation in response to SNP.

Recent investigations have indicated that basal NO activity may contribute to the resting venous tone. In a study involving awake rats, L-NG-monomethyl arginine (L-NMMA) caused a dose-dependent rise in the mean circulatory filling pressure, which was reversed by L-arginine administration (39). The endothelium regulates arterial and venous tone in a similar way. In the bovine pulmonary vascular bed (40) and in ovine pulmonary vessels, NO preferentially regulates the venous tone. Bäck et al. (41) have shown that acetylcholine elicits endothelium-dependent relaxation that is greater in porcine pulmonary veins compared to arteries.

The NO released by arteries and veins enhances cGMP levels via SGC stimulation. It has been proven that in both porcine pulmonary arteries and veins the basal tension increased after the addition of the NOS inhibitor L-NOARG, whereas indomethacin, which inhibits prostanoid production by cyclooxygenase alone, did not modify the basal tone. These findings suggest that in the porcine pulmonary vasculature, NO, but not the cyclooxygenase pathway, regulates the basal tone. The differences in NO regulation between porcine pulmonary arteries and veins are due to the fact that larger NO amounts are released from the veins compared to arteries, rather than to a difference in sensitivity to either NO or cGMP between the two preparations. This observation is supported by a previous biochemical study that demonstrated both a greater basal NO release and a larger quantity of constitutive NO protein in porcine pulmonary veins compared to arteries. In addition, a lesser degree of 
cGMP metabolism was detected in veins compared to arteries (42). Evidence that SNP-induced relaxation is similar in arteries and veins was also provided. Interestingly, the biochemical differences in phosphodiesterase activity may not affect the functional responses.

\section{Effect of NO donors on veins}

Vasoactive drugs that interfere with the body's venous tone have profound effects on hemodynamics and blood pressure. This is exemplified by the occurrence of postural hypotension following administration of drugs that cause venodilation either directly (e.g., nitrovasodilators) or indirectly by interfering with the activities of the sympathetic nervous system (e.g., $\alpha$-adrenoceptor antagonists and ganglionic blockers). NO donors are pharmacologically active substances that release NO in vivo or in vitro. The classical NO donors are nitroglycerin and SNP, which exert an important therapeutic effect on the treatment of many cardiovascular disorders such as angina pectoris and hypertension. A major clinical benefit of NO donors is their venodilating effect, which culminates in reduced venous return, cardiac preload, high blood pressure, and decreased myocardial oxygen demand. Currently, available NO donors employed in the clinical setting are more potent vein dilators compared to the resistance vasculature, and this vascular profile contributes to their efficacy in the treatment of angina and heart failure (43). It has been hypothesized that the increased sensitivity of veins to NO donors compared to resistance arteries is related to the degree of basal endogenous NO-mediated dilatation in these vessels.

Contrary to resistance vessels, veins exhibit minimal basal NO, and this might lead to increased venous vascular smooth muscle sensitivity to NO donors (44). Secondary to the up-regulation of the NO transduction pathway in vascular smooth muscle, NO stimulates sGC present in vascular smooth muscle to synthesize cGMP. In the presence of endogenously synthesized NO, there is evidence that sGC is down-regulated, resulting in reduced responsiveness to NO donors (45).

\section{Nitrite, nitrate and nitric oxide}

The half-life of NO in blood is thought to be very short, mainly due to its rapid inactivation after scavenging reactions involving hemoglobin, myoglobin, and other radicals. Therefore, NO has been regarded as an autocrine and paracrine signaling molecule with effects in the close vicinity of its production site only. More recently, it has been suggested that $\mathrm{NO}$ can combine with other compounds that can function as stable NO carriers, thereby conserving its bioactivity. A major pathway for NO inactivation is its oxidation to nitrite and nitrate, which can be considered endocrine molecules.

The nitrite anion $\left(\mathrm{NO}_{2}{ }^{-}\right)$represents an interesting constituent of the nitrogen oxides $\left(\mathrm{NO}_{x}\right)$ family. Together with nitrate $\left(\mathrm{NO}_{3}{ }^{-}\right), \mathrm{NO}_{2}^{-}$is predominantly known as an undesirable residue in food with carcinogenic effects (46) or as an endogenous NO oxidation metabolite under normal physiological conditions (47). $\mathrm{NO}_{2}$ - has long been believed to be relatively inert at the low micromolar levels that are normally found in vivo. In early in vitro studies, as reported by Furchgott and Bhadrakom (48), high $\mathrm{NO}_{2}^{-}$concentrations $(\approx 100 \mu \mathrm{M})$ were typically used to induce aortic ring relaxation or to activate purified $\mathrm{SGC}$, the enzyme that catalyzes the conversion of guanosine triphosphate (GTP) to cGMP and that mediates NO vasorelaxation (49). The high $\mathrm{NO}_{2}$ - concentrations required for vasodilatation of aortic ring bioassay systems, at room oxygen and neutral $\mathrm{pH}$, has led to the dismissal of $\mathrm{NO}_{2}^{-}$as a physiologically vasoactive mediator.

Nevertheless, it has been reported that $\mathrm{NO}_{2}{ }^{-}$can be a source of $\mathrm{NO}$ in ischemic tissues, where it is reduced back to NO. Research performed over the years by several laboratories has shown that different pathways exist to recycle this anion back into bioactive $\mathrm{NO}$ in blood and tissues, and that $\mathrm{NO}_{2}$ - is a potential supplementary $\mathrm{NO}$ source that offers therapeutic benefit (50). More recently, it has become clear that $\mathrm{NO}_{2}{ }^{-}$has a complex in vivo chemistry that is associated with NO signaling pathways, particularly with regard to the control of vasodilatation (51).

Until recently, it was generally accepted that the only pathway of $\mathrm{NO}$ release in vivo was the oxygen-dependent conversion of arginine to citrulline and NO via NOS. However, $\mathrm{NO}_{3}{ }^{-}$and $\mathrm{NO}_{2}{ }^{-}$can be viewed as storage pools supporting NO signaling during metabolic stress, with their bioactivation involving both enzymatic and non-enzymatic reactions in blood and tissues. $\mathrm{NO}_{3}$ - bioactivation entails an initial reduction to $\mathrm{NO}_{2}{ }^{-}$by symbiotic bacteria in the oral cavity (52). The commensal bacteria use $\mathrm{NO}_{3}{ }^{-}$as an electron acceptor alternative to oxygen during respiration, which culminates in $\mathrm{NO}_{3}{ }^{-}$reduction to $\mathrm{NO}_{2}{ }^{-}$by the action of nitrate reductases. In 2004, Lundberg and Govoni (53) reported that $\mathrm{NO}_{3}$ - is a substrate for systemic $\mathrm{NO}_{2}-$ generation. They tested whether inorganic $\mathrm{NO}_{3}$ - ingestion would affect the levels of salivary and systemic $\mathrm{NO}_{2}^{-}$and S-nitrosothiols, both considered to be circulating storage pools for NO. Patients presented a 4-fold increase in plasma $\mathrm{NO}_{2}{ }^{-}$after inorganic $\mathrm{NO}_{3}{ }^{-}$ingestion (53). In the same way, another study demonstrated that ingestion of beet juice, which is rich in $\mathrm{NO}_{2}-/ \mathrm{NO}_{3}{ }^{-}$, by healthy volunteers boosted the plasma levels of $\mathrm{NO}_{2}^{-}$and $\mathrm{NO}_{3}^{-}$. The study further showed that bacterial-mediated conversion of $\mathrm{NO}_{3}{ }^{-}$to $\mathrm{NO}_{2}{ }^{-}$on the tongue could significantly elevate $\mathrm{NO}_{2}$ - levels in plasma, thus accounting for cardiovascular events such as a reduction of blood pressure to $\approx 10 \mathrm{mmHg}$, which were abated when microbes were eliminated by spitting (54). Salivary-derived $\mathrm{NO}_{2}^{-}$is non-enzymatically reduced in the acidic gastric environment, to form $\mathrm{NO}$ and other nitrogen oxides. $\mathrm{NO}_{2}^{-}$ reduction to $\mathrm{NO}$ is greatly enhanced by reducing compounds 
such as vitamin $\mathrm{C}$ and polyphenols. There are numerous pathways for further reduction of this $\mathrm{NO}_{2}^{-}$to $\mathrm{NO}$. These results challenge the dogma that $\mathrm{NO}_{2}{ }^{-}$is biologically inert and instead suggest that a complete reverse pathway for $\mathrm{NO}$ generation from $\mathrm{NO}_{3}$ - exists.

Several mechanisms for $\mathrm{NO}_{2}^{-}$reduction to $\mathrm{NO}$ have been identified including: 1) Nonenzymatic disproportionation at low $\mathrm{pH}$. $\mathrm{NO}_{2}^{-}$reduction to $\mathrm{NO}$ is favored by low $\mathrm{pH}$ and a reducing milieu (55). In 1999, Zweier et al. (55) demonstrated that enzyme-independent $\mathrm{NO}$ formation occurs in biological systems under acidic conditions and is further increased in the presence of a highly reduced metabolic state. The substrate source of this $\mathrm{NO}$ is $\mathrm{NO}_{2}{ }^{-}$ rather than the NOS substrate L-arginine. Under hypoxic conditions, this $\mathrm{NO}$ accumulates in tissues and binds to a variety of cellular heme proteins. In important disease states, such as ischemia or shock, where acidosis and marked hypoxia take place, this pathway becomes the major NO source and the magnitude of $\mathrm{NO}$ generation can be much greater than that which would be found at normal NOS tissue concentrations.

2) Reduction of circulating $\mathrm{NO}_{2}^{-}$to $\mathrm{NO}$ during tissue hypoxia. Many mechanisms for the $\mathrm{NO}_{2}-$-mediated vasodilatation during hypoxia have been proposed over the past years. These are essentially based on nonenzymatic (55) or enzymatic $\mathrm{NO}_{2}^{-}$reduction to $\mathrm{NO}$ (53). Zweier et al. (55) have shown the occurrence of systemic $\mathrm{NO}$ generation from $\mathrm{NO}_{2}{ }^{-}$. They found that $\mathrm{N}^{15}$-labeled $\mathrm{NO}_{2}{ }^{-}$was reduced to $\mathrm{NO}$ in ischemic rat hearts, and that NO production was not blocked by NOS inhibitors. During global ischemia in the heart, $\mathrm{pH}$ fell to $\approx 5.5$, and under these conditions, $\mathrm{NO}_{2}{ }^{-}$reduction to $\mathrm{NO}$ was greatly accelerated. A key point of $\mathrm{NO}_{2}$ - pharmacology is that its vasodilating properties are notably enhanced during hypoxia compared to normoxia. Previous studies have suggested that the $\mathrm{NO}_{2}{ }^{-}$hypoxic vasodilatation is independent of eNOS, but depends on SGC, supporting the hypothesis that NO mediates these effects. The authors (55) proved that nitrite vasodilatation does not seem to depend on the activity of previously identified $\mathrm{NO}_{2}^{-}$reductases, such as xanthine oxidase and the mitochondrial $b c 1$ complex, which may generate $\mathrm{NO}$ from $\mathrm{NO}_{2}$ - .

3) Enzymatic conversion. Anumber of publications now state that oxidoreductase enzymes are able to convert significant amounts of $\mathrm{NO}_{2}{ }^{-}$to $\mathrm{NO}$, in particular xanthine oxidase and aldehyde oxidase (56). Xanthine oxidoreductase is known to reduce molecular oxygen to superoxide $\left(\mathrm{O}_{2}^{-}\right)$, but at low oxygen tensions and $\mathrm{pH}$ values this enzyme can also reduce $\mathrm{NO}_{2}{ }^{-}$to $\mathrm{NO}$ at the molybdenum site of the enzyme. Li et al. (56) have shown that administration of the xanthine oxidase inhibitor oxypurinol or of the aldehyde oxidase inhibitor raloxifene considerably diminished NO generation from $\mathrm{NO}_{2}^{-}$in the heart and liver. $\mathrm{NO}$ formation rates were dramatically increased with decreasing $\mathrm{pH}$ and lower oxygen tension.

4) Reduction process. It is possible that $\mathrm{NO}_{2}$--derived
$\mathrm{NO}$ acts not only through sGC, but is also generated by SGC in a reductive process (57). It has been reported that both vasorelaxation and $\mathrm{NO}$ generation were abolished by an sGC inhibitor (ODQ, $10 \mu \mathrm{M})$. Therefore, Alzawahra et al. (57) concluded that the dose-dependent vasodilating effects of exogenous inorganic $\mathrm{NO}_{2}^{-}$are due to $\mathrm{NO}$ formation by a process mediated by SGC and/or other heme enzymes under aerobic conditions. Reduction by deoxyhemoglobin has also been reported. During $\mathrm{NO}_{2}^{-}$infusion into the human forearm circulation, the observed vasodilating effects are associated with eNO formation in blood, as measured by the rate of iron-nitrosylated hemoglobin (NO bound to the heme of hemoglobin) formation during artery to vein transit. The NO formation rate increases as the hemoglobin oxygen saturation falls, suggesting a hypoxia-regulated mechanism for $\mathrm{NO}_{2}{ }^{-}$bioactivation (50). These same authors published the first report demonstrating vasodilatation in humans prompted by $\mathrm{NO}_{2}$ - infusions at near physiological levels. Experiments have also pointed to the novel role of deoxyhemoglobin as a functional $\mathrm{NO}_{2}^{-}$reductase that contributes to vasodilatation. This complex was considered to be the largest intravascular storage pool for NO, and it was deduced that $\mathrm{NO}_{2}$ - bioactivation to $\mathrm{NO}$ could promote vasodilatation in regions with oxygen debt in the human circulation. Myoglobin has high affinity for oxygen and a low heme redox potential, which aids rapid $\mathrm{NO}_{2}^{-}$reduction to $\mathrm{NO}$ when it is deoxygenated. In fact, deoxymyoglobin will reduce $\mathrm{NO}_{2}$ - to $\mathrm{NO}$ thirty times faster than hemoglobin.

All in all, the findings of the several studies mentioned here reinforce the view that $\mathrm{NO}_{2}$ - is not simply an undesired residue in food but that it might have a crucial role in maintaining healthy, particularly in hypoxia. The $\mathrm{NO}_{3}^{-}-\mathrm{NO}_{2}-\mathrm{NO}$ pathway is very important when oxygen availability is reduced and NOS activity is decreased, when $\mathrm{NO}_{2}-$ reduction to $\mathrm{NO}$ becomes more evident. It is possible that increasing knowledge about $\mathrm{NO}_{2}$--derived $\mathrm{NO}$ can lead to the development of new drugs for use in cardiovascular medicine. $\mathrm{NO}_{2}$--based pharmaceuticals that selectively deliver $\mathrm{NO}$ to ischemic areas only are indeed an interesting alternative approach.

\section{Nitric oxide bioconversion}

NO can exist in a variety of molecular forms; for instance, as free radical $\left(\mathrm{NO}^{0}\right)$ and nitrosyl $\left(\mathrm{NO}^{-}\right)$or nitrosonium ions $\left(\mathrm{NO}^{+}\right)$, with the form depending on the NO source. Hence, the NO released from NO donors can differ from the NO produced in the endothelial cells. This could explain the differences in potency and efficacy of the known NO donors when inducing vasodilatation. NO donors are pharmacologically active substances that release $\mathrm{NO}$ in vivo or in vitro. NO delivery can occur through many kinds of stimuli, depending on the NO donor structure.

In the case of the NO donor SNP, an NO molecule is coordinated to the iron metal, forming a square bipyramidal 
complex with five cyanide anions $\left(\mathrm{CN}^{-}\right)$. It has been demonstrated that SNP does not release NO spontaneously, but NO release from SNP happens when SNP is irradiated with visible light at rates linearly proportional to the light intensity. NO production by SNP also requires enzymatic metabolism. These enzymes are present in the vascular tissue, and therefore the use of reducing agents is another way to achieve NO release from SNP (58). NO generation is preceded by $\mathrm{CN}^{-}$release, which is toxic to cells and is thus an important limitation of the pharmacological use of SNP.

Other NO donors, namely nitrosyl ruthenium complexes, investigated in our laboratory also provide different means of NO release. The NO donor trans- $\left[\mathrm{RuCl}\left([15] \mathrm{aneN}_{4}\right) \mathrm{NO}\right]^{2+}$ requires chemical reduction to induce relaxation. This mechanism was demonstrated by Bonaventura et al. (14) when the concentration-response curves for trans-[RuCl([15] ane $\left.{ }_{4}\right) \mathrm{NO}^{2+}$ were evaluated in the absence of reducing agent. Unlike the last complex, the nitrosilo-terpyridine-phenylene-diamine ruthenium (II) ion complex ([Ru(terpy)(bdq) $\left.\mathrm{NO}^{+}\right]^{3+}$ ) has its vascular relaxation effect accelerated in the presence of light (15), but it does not need to be reduced to elicit vasorelaxation. cis-[RuCl(bpy $\left.)_{2}(\mathrm{NO})\right]\left(\mathrm{PF}_{6}\right)(\mathrm{RUNOCL})$ is another nitro ruthenium NO complex that releases NO upon activation by light irradiation. The RUNOCL profile can be a helpful tool in therapies dealing with light activation process, such as photodynamic therapy (59).

Today, there are at least four organic nitrates of therapeutic relevance in the treatment of angina and myocardial infarction, more specifically nitroglycerin, pentaerythrityl tetranitrate, isosorbide dinitrate, and isosorbide-5-mononitrate. Nitroglycerine has been renamed glyceryl trinitrate (GTN)

\section{References}

1. Oliveira AP, Lunardi CN, Rodrigues GJ, Bendhack LM. Relaxation induced by calcium ionophore is impaired in carotid arteries from $2 \mathrm{~K}-1 \mathrm{C}$ rats due to failed effect of nitric oxide on the smooth muscle cells. Vascul Pharmacol 2009; 50: 153159.

2. Moncada S, Higgs EA. The discovery of nitric oxide and its role in vascular biology. Br J Pharmacol 2006; 147 (Suppl 1): S193-S201.

3. de Gaitani CM, de Melo MC, Lunardi CN, de S Oliveira, da Silva RS, Bendhack LM. Hypotensive effect of the nitrosyl ruthenium complex nitric oxide donor in renal hypertensive rats. Nitric Oxide 2009; 20: 195-199.

4. Bonaventura D, Oliveira FS, da Silva RS, Bendhack LM. Decreased vasodilation induced by a new nitric oxide donor in two kidney, one clip hypertensive rats is due to impaired K channel activation. Clin Exp Pharmacol Physiol 2005; 32: 478-481.

5. Furchgott RF, Zawadzki JV. The obligatory role of endothelial cells in the relaxation of arterial smooth muscle by acetylcholine. Nature 1980; 288: 373-376.

6. Rodrigues GJ, Restini CB, Lunardi CN, Neto MA, Moreira JE, to avoid the anxiety associated with ingestion of a potential explosive, and has been continuously used for the treatment of angina since 1878. GTN has also been applied to control hypotension during cardiac surgery and in congestive heart failure. Only in 2002 did Chen et al. (60) show that mitochondrial aldehyde dehydrogenase (ALDH-2) significantly metabolizes nitroglycerin in vitro and in vivo, and that inhibition of this enzyme markedly decreases the vasodilating potency of GTN. The $\mathrm{NO}_{2}^{-}$generated by ALDH-2 from its parent nitroglycerin within the mitochondria is then further metabolized by reduction to $\mathrm{NO}$ and/or by conversion to S-nitrosothiol, to promote NO-based bioactivities.

In contrast to organic nitrates and nitrate-like agents, direct NO donors release NO spontaneously, without the need for metabolism and biotransformation. The NO gas has been useful in the treatment of multiple respiratory disorders and is the first vasodilator to produce selective pulmonary vasodilatation. The compounds called NONOates have NO bound to a nucleophile, with up to $40 \% \mathrm{NO}$ content by weight. They are direct NO donors since they release $\mathrm{NO}$ at physiological $\mathrm{pH}$ and require no metabolism or redox activation. S-nitrosothiols are endogenous, naturally occurring moieties on proteins that are generated when the thiol of cysteine reacts with $\mathrm{NO}$ in the presence of an electron acceptor, to form an S-NO bond. S-nitrosothiols act as NO reservoirs, and their degradation, which may occur through a number of enzymatic systems, results in spontaneous NO release.

\section{Acknowledgments}

Research supported by FAPESP and CNPq.
Bendhack LM. Decreased number of caveolae in endothelial cells impairs the relaxation induced by acetylcholine in hypertensive rat aortas. Eur J Pharmacol 2010; 627: 251-257.

7. Rodrigues GJ, Restini CB, Lunardi CN, Moreira JE, Lima RG, da Silva RS, et al. Caveolae dysfunction contributes to impaired relaxation induced by nitric oxide donor in aorta from renal hypertensive rats. J Pharmacol Exp Ther 2007; 323: 831-837.

8. Voldstedlund M, Vinten J, Tranum-Jensen J. cav-p60 expression in rat muscle tissues. Distribution of caveolar proteins. Cell Tissue Res 2001; 306: 265-276.

9. Ribeiro MO, Antunes E, de Nucci G, Lovisolo SM, Zatz R. Chronic inhibition of nitric oxide synthesis. A new model of arterial hypertension. Hypertension 1992; 20: 298-303.

10. Bernátová I, Pechanova $\mathrm{O}$, Babal $\mathrm{P}$, Kysela $\mathrm{S}$, Stvrtina S, Andriantsitohaina R. Wine polyphenols improve cardiovascular remodeling and vascular function in NO-deficient hypertension. Am J Physiol Heart Circ Physiol 2002; 282: H942-H948.

11. Mittal CK, Murad F. Activation of guanylate cyclase by superoxide dismutase and hydroxyl radical: a physiological regula- 
tor of guanosine 3',5'-monophosphate formation. Proc Natl Acad Sci U S A 1977; 74: 4360-4364.

12. Ferezin CZ, Oliveira FS, da Silva RS, Simioni AR, Tedesco $\mathrm{AC}$, Bendhack LM. The complex trans-[RuCl([15]aneN4NO $]^{2+}$ induces rat aorta relaxation by ultraviolet light irradiation. $\mathrm{Ni}$ tric Oxide 2005; 13: 170-175.

13. Allardyce CS, Dyson PJ. Ruthenium in medicine: current clinical uses and future prospects. Platinum Metals Rev 2001; 45: 62-69.

14. Bonaventura D, de S Oliveira, Togniolo V, Tedesco AC, da Silva RS, Bendhack LM. A macrocyclic nitrosyl ruthenium complex is a NO donor that induces rat aorta relaxation. Nitric Oxide 2004; 10: 83-91.

15. De Lima RG, Sauaia M, Bonaventura D, Tedesco AC, Bendhack LM, Da Silva RS. Influence of ancillary ligand $L$ in the nitric oxide photorelease by the $[\mathrm{Ru}(\mathrm{L}) \text { (terpy)NO}]^{3+}$ complex and its vasodilator activity based on visible light irradiation. Inorg Chem 2006; 359: 2543-2549.

16. Lunardi CN, Vercesi JA, da Silva RS, Bendhack LM. Vasorelaxation induced by the new nitric oxide donor cis$[\mathrm{Ru}(\mathrm{Cl})(\mathrm{bpy})(2)(\mathrm{NO})](\mathrm{PF}(6))$ is due to activation of $\mathrm{K}(\mathrm{Ca})$ by a cGMP-dependent pathway. Vascul Pharmacol 2007; 47: 139-144.

17. da Silva RS, Marchesi MS, Khin C, Lunardi CN, Bendhack LM, Ford PC. Photoinduced electron transfer between the cationic complexes $\mathrm{Ru}(\mathrm{NH} 3) 5 \mathrm{pz} 2+$ and trans-RuCl([15] aneN4) $\mathrm{NO}^{2+}$ mediated by phosphate ion: visible light generation of nitric oxide for biological targets. J Phys Chem B 2007; 111: 6962-6968.

18. Rodrigues GJ, Lunardi CN, Lima RG, Santos CX, Laurindo FR, da Silva RS, et al. Vitamin C improves the effect of a new nitric oxide donor on the vascular smooth muscle from renal hypertensive rats. Nitric Oxide 2008; 18: 176-183.

19. Bonaventura D, de Lima RG, Vercesi JA, da Silva RS, Bendhack LM. Comparison of the mechanisms underlying the relaxation induced by two nitric oxide donors: sodium nitroprusside and a new ruthenium complex. Vascul Pharmacol 2007; 46: 215-222.

20. Bonaventura D, Oliveira FS, Lunardi CN, Vercesi JA, da Silva RS, Bendhack LM. Characterization of the mechanisms of action and nitric oxide species involved in the relaxation induced by the ruthenium complex. Nitric Oxide 2006; 15: 387-394.

21. da Rocha ZN, Marchesi MS, Molin JC, Lunardi CN, Miranda $\mathrm{KM}$, Bendhack LM, et al. The inducing NO-vasodilation by chemical reduction of coordinated nitrite ion in cis-[Ru( $\mathrm{NO}(2))$ L(bpy)(2)](+) complex. Dalton Trans 2008; 4282-4287.

22. de Barros BF, Toledo JC Jr, Franco DW, Tfouni E, Krieger MH. A new inorganic vasodilator, trans-[Ru(NO) $\left.\left(\mathrm{NH}^{3}\right)_{4}(\mathrm{POEt})_{3}\right]$ $\left(\mathrm{PF}^{6}\right)^{3}$ : hypotensive effect of endothelium-dependent and -independent vasodilators in different hypertensive animals models. Nitric Oxide 2002; 7: 50-56.

23. Fricker SP, Slade E, Powell NA, Vaughan OJ, Henderson GR, Murrer BA, et al. Ruthenium complexes as nitric oxide scavengers: a potential therapeutic approach to nitric oxidemediated diseases. Br J Pharmacol 1997; 122: 1441-1449.

24. Jia YX, Pan CS, Yang JH, Liu XH, Yuan WJ, Zhao J, et al. Altered L-arginine/nitric oxide synthase/nitric oxide pathway in the vascular adventitia of rats with sepsis. Clin Exp Pharmacol Physiol 2006; 33: 1202-1208.

25. Christensen KL, Mulvany MJ. Location of resistance arteries. $J$ Vasc Res 2001; 38: 1-12.

26. Kang KT, Sullivan JC, Sasser JM, Imig JD, Pollock JS. Novel nitric oxide synthase - dependent mechanism of vasorelaxation in small arteries from hypertensive rats. Hypertension 2007; 49: 893-901.

27. Liu H, Ledingham JM, Mullaney I, Laverty R. Endothelial function in mesenteric resistance arteries from the genetically hypertensive rat. Clin Exp Pharmacol Physiol 2002; 29: 405411.

28. Christensen FH, Stankevicius E, Hansen T, Jorgensen MM, Valverde VL, Simonsen U, et al. Flow- and acetylcholineinduced dilatation in small arteries from rats with renovascular hypertension - effect of tempol treatment. Eur J Pharmacol 2007; 566: 160-166.

29. White RM, Rivera CO, Davison CB. Differential contribution of endothelial function to vascular reactivity in conduit and resistance arteries from deoxycorticosterone-salt hypertensive rats. Hypertension 1996; 27: 1245-1253.

30. Sobey CG, Moffatt JD, Cocks TM. Evidence for selective effects of chronic hypertension on cerebral artery vasodilatation to protease-activated receptor-2 activation. Stroke 1999; 30: 1933-1940.

31. Briones AM, Alonso MJ, Hernanz R, Miguel M, Salaices M. Alterations of the nitric oxide pathway in cerebral arteries from spontaneously hypertensive rats. J Cardiovasc Pharmacol 2002; 39: 378-388.

32. Sampson LJ, Plane F, Garland CJ. Involvement of cyclic GMP and potassium channels in relaxation evoked by the nitric oxide donor, diethylamine NONOate, in the rat small isolated mesenteric artery. Naunyn Schmiedebergs Arch Pharmacol 2001; 364: 220-225.

33. Schubert R, Krien U, Wulfsen I, Schiemann D, Lehmann G, Ulfig N, et al. Nitric oxide donor sodium nitroprusside dilates rat small arteries by activation of inward rectifier potassium channels. Hypertension 2004; 43: 891-896.

34. Shepherd JT, Vanhoutte PM. Role of the venous system in circulatory control. Mayo Clin Proc 1978; 53: 247-255.

35. Greenway CV, Lautt WW. Blood volume, the venous system, preload, and cardiac output. Can J Physiol Pharmacol 1986; 64: 383-387.

36. Szasz T, Thompson JM, Watts SW. A comparison of reactive oxygen species metabolism in the rat aorta and vena cava: focus on xanthine oxidase. Am J Physiol Heart Circ Physiol 2008; 295: H1341-H1350.

37. Palmer RM, Ferrige AG, Moncada S. Nitric oxide release accounts for the biological activity of endothelium-derived relaxing factor. Nature 1987; 327: 524-526.

38. Vedernikov YP, Graser T, Tiedt N, Vikhert AM. Heterogeneity of the response of venous smooth muscle to arterial endothelium-derived relaxing factor (EDRF) in respect of the role of nitric oxide. Basic Res Cardiol 1988; 83: 122-127.

39. Glick MR, Gehman JD, Gascho JA. Endothelium-derived nitric oxide reduces baseline venous tone in awake instrumented rats. Am J Physiol 1993; 265: H47-H51.

40. Ignarro LJ, Byrns RE, Wood KS. Endothelium-dependent modulation of cGMP levels and intrinsic smooth muscle tone in isolated bovine intrapulmonary artery and vein. Circ Res 1987; 60: 82-92.

41. Bäck M, Norel X, Walch L, Gascard J, Mazmanian G, Dahlen $S$, et al. Antagonist resistant contractions of the porcine pulmonary artery by cysteinyl-leukotrienes. Eur J Pharmacol 2000; 401: 381-388.

42. Bina S, Hart JL, Sei Y, Muldoon SM. Factors contributing to differences in the regulation of cGMP in isolated porcine 
pulmonary vessels. Eur J Pharmacol 1998; 351: 253-260.

43. Collier JG, Lorge RE, Robinson BF. Comparison of effects of tolmesoxide (RX71107), diazoxide, hydrallazine, prazosin, glyceryl trinitrate and sodium nitroprusside on forearm arteries and dorsal hand veins of man. Br J Clin Pharmacol 1978; 5: 35-44.

44. Moncada S, Rees DD, Schulz R, Palmer RM. Development and mechanism of a specific supersensitivity to nitrovasodilators after inhibition of vascular nitric oxide synthesis in vivo. Proc Natl Acad Sci U S A 1991; 88: 2166-2170.

45. Filippov G, Bloch DB, Bloch KD. Nitric oxide decreases stability of mRNAs encoding soluble guanylate cyclase subunits in rat pulmonary artery smooth muscle cells. J Clin Invest 1997; 100: 942-948.

46. Mensinga TT, Speijers GJ, Meulenbelt J. Health implications of exposure to environmental nitrogenous compounds. Toxicol Rev 2003; 22: 41-51.

47. Kleinbongard P, Dejam A, Lauer $T$, Rassaf $T$, Schindler A, Picker $\mathrm{O}$, et al. Plasma nitrite reflects constitutive nitric oxide synthase activity in mammals. Free Radic Biol Med 2003; 35: 790-796.

48. Furchgott RF, Bhadrakom S. Reactions of strips of rabbit aorta to epinephrine, isopropylarterenol, sodium nitrite and other drugs. J Pharmacol Exp Ther 1953; 108: 129-143.

49. Ignarro LJ, Lippton $\mathrm{H}$, Edwards JC, Baricos WH, Hyman $\mathrm{AL}$, Kadowitz PJ, et al. Mechanism of vascular smooth muscle relaxation by organic nitrates, nitrites, nitroprusside and nitric oxide: evidence for the involvement of S-nitrosothiols as active intermediates. J Pharmacol Exp Ther 1981; 218: 739749.

50. Cosby K, Partovi KS, Crawford JH, Patel RP, Reiter CD, Martyr S, et al. Nitrite reduction to nitric oxide by deoxyhemoglobin vasodilates the human circulation. Nat Med 2003; 9: 1498-1505.

51. Gladwin MT, Raat NJ, Shiva S, Dezfulian C, Hogg N, KimShapiro DB, et al. Nitrite as a vascular endocrine nitric oxide reservoir that contributes to hypoxic signaling, cytoprotection, and vasodilation. Am J Physiol Heart Circ Physiol 2006; 291: $\mathrm{H} 2026-\mathrm{H} 2035$.

52. Lundberg JO, Weitzberg E, Cole JA, Benjamin N. Nitrate, bacteria and human health. Nat Rev Microbiol 2004; 2: 593602.

53. Lundberg JO, Govoni M. Inorganic nitrate is a possible source for systemic generation of nitric oxide. Free Radic Biol Med 2004; 37: 395-400.

54. Webb AJ, Patel N, Loukogeorgakis S, Okorie M, Aboud Z, Misra S, et al. Acute blood pressure lowering, vasoprotective, and antiplatelet properties of dietary nitrate via bioconversion to nitrite. Hypertension 2008; 51: 784-790.

55. Zweier JL, Samouilov A, Kuppusamy P. Non-enzymatic nitric oxide synthesis in biological systems. Biochim Biophys Acta 1999; 1411: 250-262.

56. Li H, Cui H, Kundu TK, Alzawahra W, Zweier JL. Nitric oxide production from nitrite occurs primarily in tissues not in the blood: critical role of xanthine oxidase and aldehyde oxidase. J Biol Chem 2008; 283: 17855-17863.

57. Alzawahra WF, Talukder MA, Liu X, Samouilov A, Zweier JL. Heme proteins mediate the conversion of nitrite to nitric oxide in the vascular wall. Am J Physiol Heart Circ Physiol 2008; 295: H499-H508.

58. Bates JN, Baker MT, Guerra R Jr, Harrison DG. Nitric oxide generation from nitroprusside by vascular tissue. Evidence that reduction of the nitroprusside anion and cyanide loss are required. Biochem Pharmacol 1991; 42 (Suppl): S157S165.

59. Lunardi CN, Cacciari AL, Silva RS, Bendhack LM. Cytosolic calcium concentration is reduced by photolysis of a nitrosyl ruthenium complex in vascular smooth muscle cells. Nitric Oxide 2006; 15: 252-258.

60. Chen Z, Zhang J, Stamler JS. Identification of the enzymatic mechanism of nitroglycerin bioactivation. Proc Natl Acad Sci U S A 2002; 99: 8306-8311. 